\title{
Teoria e História: Notas Críticas sobre o Tema da Mudança Institucional em Douglass North
}

\author{
Theory and history: critical notes on the Institutional \\ Change theme in Douglass North
}

SEBASTIÃO C. VELASCO E CRUZ*

RESUMO: Em seu livro Institutions, Institutional Change and Economic Performance North se propõe explicitamente a tarefa de formular uma teoria sistemática sobre a mudança institucional. Ao fazer isso, ele abandona alguns dos pressupostos neoclássicos que até então estiveram a informar a sua obra, o que lhe torna possível transformar em problemas genuínos de pesquisa uma série de fenômenos anteriormente encarados como simples anomalias, fatos brutos que, embora reconhecidos, mantinham-se como elementos exógenos ao modelo. Inserindo o argumento do autor na linha de reflexão tecida por ele ao longo do tempo, o objetivo do artigo é o de apresentá-lo com fidelidade e submetê-lo à crítica, salientando as dificuldades que dele se originam quando formulamos perguntas sobre o desenrolar dos conflitos que acompanham e impulsionam os processos históricos de mudança institucional. Trata-se, portanto, de um artigo teórico-metodológico que põe em comunicação duas disciplinas vizinhas (a Economia e a Ciência Política) e duas vertentes do Novo Institucionalismo (nacionalista e histórica).

PALAVRAS-CHAVE: Douglass North; economia institucional; mudança institucional; instituições econômicas internacionais; neoliberalismo.

ABSTRACT: In his book Institutions, Institutional Change and Economic Performance North explicitly sets out the task of formulating a systematic theory of institutional change. In doing so, he abandons some of the neoclassical assumptions that had so far been informing his work, which makes it possible for him to turn into genuine research problems a series of phenomena formerly regarded as simple anomalies, which, though acknowledged, still held. as elements exogenous to the model. By inserting the author's argument in the line of reflection woven by him over time, the aim of the article is to present it faithfully and to criticize it, highlighting the difficulties that arise from it when we ask questions about the conflicts that accompany and drive the historical processes of institutional change. It is, therefore, a theoretical-methodological article that communicates two neighboring disciplines (Econom-

\footnotetext{
* Instituto de Filosofia e Ciências Humanas da Universidade Estadual de Campinas - IFCH-Unicamp, Campinas, SP/Brasil, e-mail: svelasco@globo.com.
} 
ics and Political Science) and two strands of the New Institutionalism (shareholder and historical).

KEYWORDS: Douglass North; institutional economics; institutional change; international economic institutions; neoliberalism.

JEL Classification: B52.

Contrariamente a seu colega Ronald Coase, que apenas ao fim do percurso teria tomado consciência da direção em que suas elucubrações o conduziam, em sua palestra no ciclo que deu origem ao livro Lives of the Laureates Douglass North nos conta que, desde o momento em que decidiu ser um economista, foi guiado por um único e bem definido objetivo: entender o que tornava as economias ricas ou pobres, como condição sine qua non para melhorar seu desempenho. $\mathrm{Na}$ tentativa de responder a essa questão, North foi levado do marxismo aos mistérios da ciência cognitiva, em um caminho pontilhado por obras que lhe valeram notoriedade internacional e, finalmente, o Prêmio Nobel. Mas aqui estaremos considerando apenas os resultados de uma de suas etapas: a que se expressa no livro Institutions, Institutional Change and Economic Performance, de 1990. E, ainda assim, com uma importante ressalva. Nessa obra, cujo volume - bastante modesto - não oculta o tamanho enorme da ambição, interessa-nos essencialmente um aspecto: $o$ tratamento dado ao tema da mudança institucional.

Assim definido, o interesse que animou a leitura do livro dita igualmente os termos da presente exposição. Com efeito, não se encontrará aqui uma apresentação sistemática (ou uma análise crítica) do conjunto de argumentos desenvolvidos na obra; tampouco será respeitada a ordem que a esta foi conferida por seu autor. Pelo contrário, tendo-a desagregado em seus elementos, passaremos a introduzi-los seletivamente no texto, à medida que sejam necessários à clara compreensão do problema que nos ocupa, e na seqüência tida por nós como a mais adequada tendo em vista esse resultado.

Ainda nessas considerações preliminares, cabe indicar com toda a clareza: o interesse cognitivo que nos levou à leitura de North e que estará informando a discussão subseqüente - a busca de ferramentas analíticas para melhor entender a grande transformação em curso na economia mundial nas últimas décadas — nos põe a léguas de distância das motivações de North. Explicitar essa diferença é preciso, porque não cabe julgar um autor por não responder a perguntas que não são as suas. A constatação do silêncio, se ele existe, é pertinente, mas apenas como indicação dos limites externos do campo explorado em sua obra. A crítica deve necessariamente partir dos problemas levantados pelo autor, nos termos por ele formulados. Só depois de realizado o exame interno (coerência lógica de seus argumentos) e externo (sua adequação aos dados) da elaboração intelectual em causa cabe voltar aos supostos que a sustentam, indicando a necessidade de substituí-los por outros, cuja superioridade o crítico tratará de sustentar. Convém fixar desde o início essa regra, à qual procuraremos nos manter fiéis ao longo deste trabalho. 
Extremamente ambicioso, na aparente modéstia do ato que o prepara, o roteiro delineado no parágrafo acima não será seguido integralmente nestas páginas. Nos limites de tempo e de espaço de que dispomos, propomo-nos apenas a reconstruir o argumento de North e a formular algumas observações críticas — sem o compromisso de desenvolvê-las sistematicamente e de todo ausente a pretensão de substituir sua teoria por outra mais coerente e mais poderosa.

Isso posto, vamos ao texto de North. O objetivo que ele persegue, já conhecemos: trata-se, mais uma vez, de tentar entender o desempenho diferencial das economias, ao longo do tempo (e do espaço). Mas no livro em apreço esse problema geral, que domina toda a sua obra, traduz-se em perguntas novas. Não se tratará mais de responder à questão da mudança econômica em uma dada quadra histórica (desafio que o levou ao encontro das instituições e ao reconhecimento de sua eficácia), mas de formular um quadro de referência teórico que nos permita decifrar a natureza das instituições, especificar as suas conseqüências e explicar os processos por meio dos quais elas se transformam. Uma breve referência a momentos anteriores de sua trajetória nos ajudará a esclarecer o significado que essas questões assumem para North, e a maneira como ele as aborda.

Aqui, o elemento básico é a sua formação em economia neoclássica, e o silêncio desta em relação aos parâmetros institucionais do mercado. Ora, confrontado permanentemente com a variedade dos padrões de comportamento econômico e com a sua mutabilidade, na condição de historiador da economia, a tarefa a que, desde o início, North se propôs foi de explicar esses fenômenos com os recursos da análise econômica, mas levando em conta as variações no contexto institucional. Foi essa a via que ele percorreu para localizar nos direitos de propriedade o elo decisivo na cadeia causal que conduziria as economias norte-européias ao capitalismo. Em The Rise of the Western World, obra publicada em 1973, já encontramos os rudimentos de uma teoria das instituições e da mudança institucional. As instituições reduzem a incerteza e os custos de transação envolvidos na atividade econômica, tornando possível a coordenação dos agentes e a operação eficiente dos mercados; a variação nos preços altera marginalmente o poder de barganha dos atores e, no decurso do tempo, provoca mudanças mais ou menos pronunciadas nas instituições que moldam a economia considerada. ${ }^{1}$ A trajetória da Inglaterra entre os séculos XIII e o XVII ilustra com perfeição o esquema acima delineado. Determinada em grande medida pelas tendências demográficas, a variação nos preços ou na escassez relativa dos fatores (terra, alimentos, trabalho) desequilibrava, de múltiplas formas, as relações no interior do feudo, induzindo, ao cabo de um longo processo de mudanças cumulativas, o crescimento das cidades, a monetarização dos vínculos entre senhores e camponeses, a criação de um mercado de terras e a difusão de métodos de cultivo mais eficazes. Implicados - como causa e conseqüência - nesses desenvolvimentos, arranjos institucionais e novos direitos de

\footnotetext{
${ }^{1}$ Douglass C. North e Robert P. Thomas (1973) The Rise of the Western World. A New Economic History, Cambridge, Cambridge University Press.
} 
propriedade criando incentivos que canalizavam o esforço econômico dos indivíduos em direção a atividades em que a taxa de retorno privado e a taxa de retorno coletivo se aproximavam (p. 1).

Nem todas as economias, porém, ingressaram na modernidade de forma tão virtuosa. O exemplo típico em contrário é o da Espanha, onde a Coroa, ávida de recursos para financiar as guerras de seu projeto grandioso de Império, esvaziou as cortes, desenvolveu um sistema impositivo que promovia os monopólios, sufocava as inovações e inibia a mobilidade dos fatores, fazendo declinar a produtividade econômica e condenando o país ao atraso.

O caso espanhol fornecia a contraprova necessária para corroborar a teoria, mas ao mesmo tempo apontava os limites desta. Pois associar direitos de propriedade ineficientes e necessidades fiscais do Estado era dar uma explicação ad hoc, de todo estranha ao quadro de referência em que se movia a análise.

Essa anomalia parece constituir o elemento dinamizador do programa de trabalho de Douglass North. Cinco anos depois do aparecimento do livro antes referido, ele o definia nos termos que se seguem:

"to analyse the parameters held constant by the (neoclassical) economist. If economic history is a theory of choice subject to specified constrains, a task of economic history was to theorize about those evolving constrains." 2

No livro Structure and Change in Economic History, de 1981, North dava um passo importante nesse rumo, ao abandonar o suposto da eficiência das instituições. Os detentores do poder político definem direitos de propriedade movidos por seus interesses e de acordo com seus próprios critérios; não surpreende que o resultado de sua ação seja quase sempre uma estrutura que eleva os custos de transação e cria obstáculos ao crescimento econômico.

"From the redistributive societies of ancient Egyptian dynasties throughout the slavery system of Greek and Roman world to the medieval manor, there was persistent tension between the ownership structure which maximized the rents to the ruler (and his group) and an efficient system that reduced transaction costs and encouraged economic growth. The fundamental dichotomy is the root cause of the failure of societies to experience sustained economic growth." ${ }^{3}$

Mas restava em aberto o problema: se no longo prazo o mecanismo da concorrência seleciona as organizações mais eficientes e induz a convergência em torno das normas que elas expressam, como quer o argumento neoclássico, como

\footnotetext{
${ }^{2}$ Douglass North, "Structure and performance: the task of economic history", Journal of Economic Literature, 16, 1978, p. 693.

${ }^{3}$ D. North (1981), Structure and Change in Economic History. New York. W. W. Norton \& Co, p. 25.
} 
entender a persistência continuada dos modelos socioeconômicos fracassados? Nove anos mais tarde, em Institutions, Institutional Change and Economic Performance, esse é o enigma que North tentará decifrar.

Devemos levar em conta essa relação tensa, mas umbilical, com a economia neoclássica para entender a maneira como ele será abordado. Sim, porque embora a critique e dela se afaste em vários pontos e de muitas maneiras, a economia neoclássica continua constitutivamente presente na obra tardia de North - como quadro de referência no contexto do qual formula seus problemas e "língua materna", à qual retorna constantemente em busca dos instrumentos conceituais de que necessita para pensá-los.

Podemos constatar esse fato já na declaração de princípio que abre o seu livro:

"Defining institutions as the constrains that human beings impose on themselves makes the definition complementary to the choice theoretic approach of neoclassical economic theory... The strength of microeconomic theory is that it is constructed on the basis of assumptions about individual behavior (even though I shall argue for a change in these assumptions...)

E no argumento infeliz que invoca para apoiá-lo:

"Institutions are a creation of human beings. They evolve and are altered by human beings; hence our theory must begin with the individual." ${ }^{4}$

Como se algum aspecto da realidade social pudesse constituir-se na ausência de intervenção humana, ou como se alguma mente secularizada imaginasse o contrário.

Podemos confirmá-lo ao observar o uso canhestro de categorias da análise neoclássica a esferas de problemas e a campos semânticos que originalmente lhes eram estranhos, e que só as comportam como metáforas vagas e ineptas, como nas passagens que se seguem:

“...internally enforced code of conduct [i.e, códigos morais] only have meaning in terms of informal constraints, altering choice when the individual gives up wealth or income for some other value in his or her utility function."

"More difficult is to explain internally enforced codes of conduct. It is difficult because one must devise a model that predicts choices in the context of trade-off between wealth and other values."

"What determines how much people will pay to express and act on their convictions? We seldom know much about the elasticity function or shifts in the function." 5

\footnotetext{
${ }^{4}$ D. North, Institutions, Institutional Change and Economic Performance, p. 5.

${ }^{5}$ Ibid., pp. 40, 41-2, 44.
} 
Em todas elas, problemática não é apenas a agressão lingüística contida na simples idéia de que se pudesse calcular o ponto exato em que o cruzamento do interesse pecuniário e do sentimento moral levaria o indivíduo a escolher o primeiro - uma soma bastante elevada — em traição aos segundos — digamos, sua família, sua fé ou sua pátria. Tão ou mais grave do que isso é o emprego de conceitos de conteúdo técnico preciso - "função de utilidade", "elasticidade da função" em contextos tais que os seus requisitos lógicos — aditividade, divisibilidade, independência do contexto - estão ausentes. ${ }^{6}$

O próprio North explicita a vinculação permanente com a teoria neoclássica ao anunciar o balanço que faz de sua empreitada:

"In the section that follow I (1) specify what changes must be made in neoclassical theory to incorporate institutional analysis into the theory, (2) outline the implications for the static analysis of economic performance, and (3) explore the implications of institutional analysis for the construction of a dynamic theory of long-run economic change." 7

A economia institucional de North nada tem de iconoclasta. Ele não quer demolir, nem sequer abandonar um terreno batido para explorar novas paragens, armado de outras metáforas. Sua tarefa é a de um reformador moderado. O procedimento que adota para esse fim é bastante simples. Identificando dificuldades da teoria neoclássica no trato de certos problemas - ou questões por ela silenciadas - passa a reexaminar os seus supostos, a fim de introduzir-lhe as alterações necessárias para acomodar os fenômenos problemáticos. A expectativa é de que por essa via a tradição, que é a sua, venha a ser enriquecida. A idéia de romper com ela não parece tentá-lo.

"My theory of institutions is constructed from a theory of human behavior combined with a theory of the costs of transacting." ${ }^{8}$ Esta declaração abre um atalho que nos leva diretamente ao núcleo da obra de North.

\footnotetext{
6 "La economia... ha tratado de simplificar y unificar los fenómenos del mundo de los negocios mediante la escala general, de la medición enviada por el cielo, de valor de cambio. Mediante el valor de cambio, todo, qualquier clase, color, aptidud y forma puede reducirse a una cantidad escalar. Por mor de la aditividad, todas las distinciones, especialismos, identidades pueden borrarse." "Los términos de valuación y cambio son operacionalmente inseparables. Valuar algo es nombrar el número de unidades de alguna otra cosa por la cual uno estaria dispuesto y solo dispuesto a cambiarla." G. L. S. Shackle, Epistemica y Economia, pp. 65, 139. Mas onde está o mercado e qual o preço de troca que ele define para as "unidades comportamentais normativamente orientadas"?

${ }^{7}$ D. North, Institutions, Institutional Change..., op. cit., p. 107.

${ }^{8}$ Ibid., p. 27. No artigo de 1978 antes citado, ele era bem mais incisivo. "We have much to learn from them [Veblen, Ayres e Marx], but not by abandoning neoclassical theory. Neoclassical theory has made
} 
Consideremos separadamente cada um desses ingredientes. A economia neoclássica, como já observado, ignora as instituições, tomando-as como parâmetros exogenamente dados. Sobre essa base, procede à simplificação heróica que consiste em abstrair toda dimensão qualitativa dos fenômenos que observa, reduzindo estes a sua expressão numérica por intermédio do conceito de valor de mercado, ou valor de troca. O mundo rarefeito que resulta dessa idealização, ela passa a explorálo com o poderoso instrumento da análise matemática (o cálculo integral). Partindo de alguns axiomas sobre a natureza das preferências do consumidor, das relações técnicas entre insumos e produto e da relação de troca mercantil, busca demonstrar que, em um sistema onde as decisões sobre a produção e o consumo são descentralizadas e onde produtores e consumidores competem entre si em um mercado tão grande que nenhum deles pode isoladamente afetar os preços, os recursos seriam alocados eficientemente, i.e., seria impossível aumentar o valor agregado da produção, ou melhorar a posição de uma pessoa ou algum grupo sem prejudicar outro(s) membro(s) da coletividade.

As qualificações de North incidem sobre vários aspectos dessa construção. Em primeiro lugar, deve ser abandonada a suposição, nela subjacente, de um processo de troca sem friç̧ão, no qual os direitos de propriedade são perfeitamente especificados, sem nenhum ônus para as partes concernidas; um processo em que a informação é igualmente perfeita e/ou plena e gratuitamente acessível. Nessa parte de seu argumento, North trabalha basicamente com a noção introduzida por Coase de custos de transação. Todo ato de troca envolve a aferição dos atributos dos bens nele envolvidos, bem como garantias de que os acordos celebrados serão efetivamente cumpridos. As atividades desenvolvidas com vista a esses fins têm custos variáveis, que podem ser bastante elevados dependendo do caso e das circunstâncias: são, estes, custos de transação. North procura ir além de Coase, ao perguntar sobre o que há de custoso nas atividades que implicam custos de transação e ao sugerir alguns dos efeitos que a contemplação desse fator pode ter sobre o edifício da microeconomia, mas não precisamos acompanhá-lo nesse passo.

Em segundo lugar, há que se modificar vários dos supostos neoclássicos referentes ao comportamento dos indivíduos. Para que o sistema econômico opere segundo o figurino neoclássico - i.e., em equilíbrio - os atores devem ter preferências comparáveis, estáveis, transitivas e contínuas; devem, ademais, defrontar-se repetidamente com as mesmas situações de escolha, ou com situações muito parecidas. Mas, como a observação cotidiana sugere e os estudos experimentais rigorosos vêm demonstrando, o comportamento humano é muito mais complexo — no tocante às suas motivações, aos problemas que enfrenta em sua interação com o meio ambiente e aos recursos que, para esse efeito, mobiliza. Aqui, os aspectos fundamentais dizem respeito à importância das motivações morais e altruísticas,

economics the preeminent social science by providing it a disciplined, logical analytical framework. To abandon neoclassical theory is to abandon economics as a science. The challenge is to widen its horizons...”, op. cit., p. 974. 
ao fato de que as preferências variam, e ao reconhecimento de que os indivíduos deparamse freqüentemente com situações de escolha inusitadas, em relação às quais os resultados não podem ser previstos porque a informação relevante é incompleta e/ou porque os agentes carecem dos meios necessários para processá-la. Tomados separadamente, ou em conjunto, esses elementos trazem para o proscênio o tema da incerteza, o buraco negro da teoria neoclássica. ${ }^{9}$

$\mathrm{Na}$ confluência desses dois blocos de apontamentos, a questão da coordenação social, o problema hobbesiano da ordem, como o batizou Talcot Parsons. O paralelo com o clássico do pensamento político não é abusivo. North é consciente dele e o adverte na passagem que se segue:

"It is important at this point to confront an issue that will be a focus of this study: that is, under what conditions can voluntary cooperation exist without the Hobbesian solution of the imposition of a coercive state to create cooperative solutions?" 10

É desnecessário dizer que essa questão não se coloca para a economia neoclássica. Partindo de supostos análogos, os teóricos dos jogos ofereceram uma resposta elegante para o problema ao demonstrar que em jogos repetidos, com pequeno número de participantes, cada um deles provido de informação completa sobre as preferências dos demais, nessas condições indivíduos maximizantes escolheriam cooperar. Mas sua contribuição é limitada, porque já na definição do problema eles desconhecem as dificuldades antes levantadas.

"Game theory highlights the problems of cooperation and explores specific strategies that alter the payoff to the players. But there is a vast gap between the relatively clean, precise, and simple world of game theory and the complex, imprecise, and fumbling way by which human beings have gone about structuring human interaction.”11

Nas condições de incertezas prevalentes na vida real, indivíduos isolados, tentando calcular separadamente suas respectivas utilidades, não teriam como coordenar suas ações, muito menos cooperar - salvo no interior de grupos muito reduzidos. Não obstante, o mundo moderno existe e se caracteriza pelo entrelaçamento de infinidade de cadeias de trocas impessoais. Como entender isso? A resposta que North dá a tal pergunta põe em foco as instituições e as estruturas institucionais. A coordenação é possível porque os indivíduos não se confrontam em um espaço abstrato onde as únicas coisas a contar são as suas preferências e o conjunto das alternativas que cada situação de escolha lhes oferece.

\footnotetext{
${ }^{9}$ A esse respeito, cf. o importante artigo de Jens Beckert "What is sociological about economic sociology? Uncertainty and the embeddedness of economic action”, Theory and Society, 25 (6), 1996, p. 803-40.

${ }^{10}$ D. North, Institutions, Institutional..., op. cit., p. 14.

${ }^{11}$ Ibid., p. 15.
} 
"In all societies, from the most primitive to the most advanced, people impose constraints upon themselves to give structure to their relations with others. Under condition of limited information and limited computational ability, constrains reduce the costs of human interaction as compared to a world of no institutions." 12

As instituições limitam o campo dos comportamentos possíveis (ou prováveis) nos encontros entre os agentes ao dotá-los de um repertório de fórmulas compartilhadas, ao definir direitos e deveres (dos quais, para o que interessa a North, os mais importantes são os direitos de propriedade), ao lhes fornecer os quadros necessários para projetar suas decisões no tempo e os meios para ajuizar os resultados alcançados.

Nesse ponto, contudo, verifica-se uma fratura. Como foi indicado no que precede, North toma como ponto de partida os indivíduos; as instituições são criadas por estes para que lhes seja possível o intercâmbio econômico e, para além dele, a vida em comum. Mas não observamos nenhum esforço da parte de North para mostrar, em termos lógicos ou substantivos, como eles poderiam chegar a tal resultado. $\mathrm{Na}$ verdade, as instituições surgem no texto de North como dados brutos. E não poderia ser diferente. Se, na ausência das instituições, os indivíduos não têm como chegar a acordos que levem à cooperação, como acordariam eles sobre as regras que lhes permitiriam cooperar em bases duráveis. $\mathrm{O}$ silêncio encobre uma clara circularidade no raciocínio, que deixaria de existir se North abandonasse o individualismo ontológico da tradição a que se filia e transitasse para o terreno da sociologia — onde o ser humano é por definição social e o indivíduo, com os atributos que esse conceito comunica, é produto relativamente recente de um processo histórico longo e atribulado. ${ }^{13} \mathrm{Ou}$ - para ficar numa hipótese menos extrema - se ele acompanhasse os economistas evolucionários, os quais, operando com outra metáfora e outro vocabulário de base (hábitos, rotinas, habilidades), evitam as aporias do paradigma racionalista. ${ }^{14}$

North é bastante vago sobre o que entende por instituições. Em 1981, ele definia o conceito nos termos abaixo:

"Institutions are a set of rules, compliance procedures, and moral and ethical behavioral norms designed to constrain the behavior of individual in the interest of maximizing the wealth or utility of principals." ${ }^{15}$

\footnotetext{
12 Ibid., p. 36.

${ }^{13}$ A esse respeito, cf. Norbert Elias, La Société des Individus. Paris, Fayard, 1987.

${ }^{14}$ Cf. Richard Nelson e Sidney G. Winter, An Evolutionary Theory of Economic Change. Cambridge, Harvard University Press, 1982; Geoffrey M. Hodgson, Economics and Institutions: A Manifesto for a Modern Institutional Economics. Philadelphia, University of Pensylvania Press, 1988.
}

${ }^{15}$ D. North, Structure and Change..., op. cit., p. 201-2. 
Mas, ao atribuir às instituições uma função precisa e ao especificá-la de forma tão estreita, essa definição era dificilmente sustentável. No livro que analisamos encontramos uma definição mais neutra e muito mais genérica.

"Institutions are the rule of the game in a society, or, more formally, are the humanly devised constrains that shape human interaction. In consequence they structure incentives in human exchange, whether political, social, or economic." 16

Note-se que nada resta nessa definição sobre a funcionalidade das instituições no tocante ao desempenho econômico da sociedade em que se inserem. North faz questão de ressaltar esse aspecto:

"Institutions are not necessarily or even usually created to be socially efficient; rather they, or at least the formal rules, are created to serve the interests of those with the bargaining power to devise new rules."

No espaço recortado pela definição proposta cabem muitas coisas, e coisas muito diversas: regras formais (leis, direitos de propriedade) e informais (convenções, códigos de comportamento); regras econômicas, sociais e regras políticas; regras cuja vigência requer a intervenção de agentes especializados; regras que se apóiam na sanção descentralizada do grupo social... As condições que assistem à emergência de algumas dessas coisas são facilmente inteligíveis - por exemplo, os dispositivos espontaneamente criados no curso da atividade comercial pelos próprios agentes, para resolver problemas de coordenação e diminuir custos de transação que a emperravam, como as letras de câmbio, os bancos de depósito ou os dispositivos da lex mercatori. Em relação a outras — os códigos internalizados de conduta, padrões morais — nossa ignorância continua abissal. ${ }^{17}$

Como fontes e fiadoras dos direitos de propriedade, as instituições políticas merecem de North atenção especial. Sua intervenção é dispensável nos casos de contratos que emergem no interior de redes de sociais de alta densidade, nas quais

\footnotetext{
${ }^{16}$ Id., Institutions, Institutional Change..., op. cit., p. 3.

${ }^{17}$ Objeto da crítica feita por Ronald Rogowski a seu livro anterior, Structure and Change in Economic History, o tema da ideologia constitui o "buraco negro" da abordagem racionalista. Não por acaso, a análise demolidora de Pizzorno toma como ponto de partida o relato de alguns comportamentos típicos em que esse fator é saliente e que, embora historicamente exaltados, parecem manifestações delirantes na perspectiva que ele critica. Não é de surpreender, portanto, que esse tema venha ganhando crescente destaque na agenda de pesquisa de um dos mais sofisticados expoentes da escola da ação racional refiro-me a Jon Elster - , que, em seu livro mais recente, percorre vastas regiões - da filosofia moral e dos clássicos da literatura à psicologia cognitiva e à psiquiatria - em busca de elementos para enfrentar esse espinhoso problema. Cf. Ronald Rogowski, "Structure, growth, and power: three rationalist accounts", in International Organization, 37 (4) 1983, p. 715-38; Alessandro Pizzorno, "Sul confronto intertemporale delle utilità", Stato e Mercato, 16, 1986, p. 3-25, Jon Elster, Alchimies of the Mind. Rationality and the Emotions, Cambridge, Cambridge University Press, 1999, e Carles Tilly, "Prisioners of the State", Daedalus. International Social Science Journal, 133, 1992, p. 329-42.
} 
os agentes dispõem de elevado conhecimento mútuo, envolvidos que estão em repetidas trocas. Sob tais condições, os custos de transação se vêem muito reduzidos, e o respeito aos acordos estabelecidos é a norma. Nas trocas impessoais tais condições estão ausentes. Nelas os custos de mensuração costumam ser grandes; o engodo, a fraude, o oportunismo são possibilidades sempre presentes.; os contratos são tipicamente incompletos - visto que sua vigência ao longo do tempo supõe inúmeros imponderáveis -, e a sanção de uma terceira parte, capaz de dirimir litígios e fazer valer suas decisões, torna-se, em conseqüência, obrigatória. Esse é o papel desempenhado, nem sempre a contento, pelo Estado.

Nem sempre a contento - colocado entre vírgulas, o aposto condensa uma desconcertante dificuldade. A cadeia que leva a ela é simples: para que economia seja eficiente é preciso que os direitos de propriedade tenham vigência, na configuração adequada - vale dizer, é necessário que canalizem a inteligência e as energias dos indivíduos para atividades produtivas, e não para a tentativa de obtenção de ganhos via redistribuição, em suas formas mais ou menos perversas. Cabe ao Estado prover tais condições. Mas os seus dirigentes não são teleguiados; como todos os demais eles buscam maximizar suas utilidades. Sendo assim, a pergunta se impõe: como nos assegurar contra o oportunismo, a irresponsabilidade ou a simples miopia dos governantes? Como impedir que os donos do poder empreguem a força do Estado para promover seus próprios interesses, em detrimento da sociedade? Quem controla os controladores e como o faz? Trata-se da velha questão dos federalistas, que responderam com a fórmula canônica conhecida de todos nós. Mas duzentos anos de experiência e crítica não alimentam certezas... E North conclui subscrevendo o ceticismo de Riker, que se expressa na passagem abaixo:

"But every time I convince myself that I have found an instance in which constitutional forms do make a difference for liberty my discovery comes apart in my hand.... The question is: Does constitutional structure cause a political condition and a state of public opinion or does political condition and a state of public opinion cause the constitutional structure? This sounds at first like the chicken and egg problem in which there is no causal direction; but I think that usually there is a cause and that constitutional forms are typically derivative. It seems probable to me that public opinion usually causes constitutional structure, and seldom, if ever, the other way around. As Rousseau contended, it is in the end the law that is written in the hearts of the people that counts." ${ }^{18}$

O que não deixa de ser irônico, para quem parte a decifrar o mundo com o modelo do ator auto-interessado e reconhece de pleno sua impotência diante dos comportamentos a ele estranhos, cuja importância nem por isso se escusa de regis-

\footnotetext{
18 William Riker, “Comments on Vincent Ostrom's paper”, Public Choice, 27, 1976, p. 13-5, apud., D. North, Institutions, Institutional Change..., op. cit., p. 60.
} 
trar. O próprio das instituições é varar o tempo; não obstante elas se transformam. As ações que respondem por isso são desencadeadas por agentes individuais - empresários econômicos ou políticos - em reação aos incentivos emanados da infraestrutura institucional na qual operam. O principal acicate da mudança institucional é a alteração dos preços relativos, conforme indicado em outro lugar. Aliado a este, e em permanente interação com ele, um fator menos palpável: a mudança nos gostos ou nas preferências. Mas não só. Os movimentos de preços chegam até nós por meio de esquemas mentais, que determinam a percepção que temos deles, e nossa maneira de interpretá-los. Já aí se faz presente um terceiro elemento: as idéias, os conceitos, os quadros cognitivos e normativos que medeiam nossa relação com a realidade.

Já tivemos oportunidade de indicá-lo - North reconhece explicitamente a efetividade do fator ideológico. E o faz mais amplamente agora, ao discutir o movimento abolicionista em conexão com o tema da mudança institucional. A interdição do tráfico e a supressão do trabalho escravo têm relação, sem dúvida, com mudanças nos preços relativos, mas não se explicam inteiramente por estas. $\mathrm{O}$ sentimento de rejeição moral que alimentava o movimento antiescravista em todo o mundo no século XIX foi importante na produção de tal resultado. Naturalmente, o tema da escravidão prestava-se à manipulação dos políticos, que o exploravam em função de seus interesses próprios - ou dos grupos e regiões que representavam. Mas só podiam fazê-lo porque escorados em um movimento de opinião sobremaneira forte.

Bastante enfático, esse reconhecimento não se desdobra, porém, em uma tentativa conseqüente de integrar a ideologia no quadro de referência que informa a análise. Pelo contrario, previamente admitida a insuficiência dos conhecimentos nesse campo, a menção ao episódio humanitarista prepara o terreno para a hipótese singela com a qual os efeitos potencialmente subversivos daquele fator serão neutralizados.

"The brief analysis of the elimination of slavery is built upon an institutional structure that allows people to express their views at little cost to themselves. I do not mean to imply that there are not occasions in which people are willing to engage in substantial sacrifices for their ideas and ideals... But a major point of this study is that institutions by reducing the price we pay for our convictions makes ideas, dogmas, fads, and ideologies important sources of institutional change" (grifos nossos). ${ }^{19}$

A mão que abre a porta é a mesma que, no instante seguinte, vai fechá-la: as pessoas têm maior propensão a seguir seus pontos de vista normativos quando os custos em que incorrem ao fazê-lo são reduzidos. Sendo o peso do fator ideológico uma função de tal variável (a importância das considerações normativas na deter-

${ }^{19}$ Ibid., pp. 85-6. 
minação do comportamento dos indivíduos), e como esta depende do grau de permissividade vigente na sociedade considerada, somos devolvidos ao terreno seguro das instituições e dos cálculos.

Nesse esquema, a mudança institucional é basicamente incremental: ela se verifica à margem, como resultado agregado da ação descentralizada dos agentes. Dada uma variação de preços e/ou de preferências, surge um desequilíbrio parcial no mercado correspondente, o qual é corrigido por meio de readaptações nos termos dos contratos firmados entre particulares. Mas as regras formais da estrutura institucional que valida os contratos e assegura o cumprimento de seus termos não podem ser alteradas dessa forma. Para mudá-las é preciso algo mais: o desencadeamento de ações concertadas voltadas a esse fim. Para North, isso ocorre quando os incentivos para agir nesse sentido superam os custos antecipados. Vale dizer, em última instância, que a mudança das instituições formais resulta dos cálculos maximizantes dos indivíduos. A partir daí, o que decide o curso do processo - se a mudança vai se produzir e com que alcance - é o poder de barganha das partes envolvidas (os que têm a ganhar e os que têm a perder com esta).

Nada disso exclui a possibilidade de mudanças descontínuas, causadas por acontecimentos traumáticos, como conquistas, revoluções ou grandes catástrofes naturais. Mas, analisando mais atentamente esses casos, constatamos que a ruptura nas regras formais tem um impacto muito menor do que se poderia imaginar. Isso se deve ao peso das normas informais que pautam o comportamento dos grupos e dos indivíduos. Nossa ignorância a respeito dos mecanismos que presidem a mudança cultural ainda é grande, mas sabemos que as normas culturais mudam em um ritmo distinto (em geral muito mais lento) do ritmo em que variam os preços ou as regras formais. As transformações dramáticas que acompanham os acontecimentos antes referidos criam, assim, uma situação de desequilíbrio, a qual será corrigida no decurso do tempo, mediante acomodações sucessivas — em ambas as direções - cujo resultado tende a ser, tipicamente, uma sociedade muito menos revolucionária.

$\mathrm{O}$ arcabouço institucional determina em grande medida a estrutura de incentivos que prevalece em uma dada sociedade. Buscando tirar o maior proveito possível das oportunidades que se lhes oferecem em tal contexto, os agentes individuais e coletivos - as organizações - desenvolvem conhecimentos e habilidades que refletem essa estrutura, sendo desigualmente recompensados segundo o seu grau de sucesso. Entre instituições e atores prevalece, pois, uma relação simbiótica. Ela é compatível com a mobilização de energias para a introdução de mudanças marginais, mas - no tocante aos atores mais bem situados, ao menos - exclui qualquer disposição para mudanças radicais. É por essa via que North vai responder à pergunta sobre a persistência das organizações socioeconômicas fadadas ao fracasso.

"The increasing returns, characteristic of an initial set of institutions that provide disincentives to productive activity will create organizations and interest groups with a stake in the existing constraints. They will shape the polity in their interests... The subjective mental constructs of the par- 
ticipants will evolve an ideology that not only rationalizes the society's structure but accounts for its poor performance. As a result the economy will evolve policies that reinforce the existing incentives and organizations. Thus, both the writings of the Economic Commission for Latin America (ECLA) and dependency theory explain the poor performance of Latin American economies on the basis of the international terms of trade... Such an explanation not only rationalizes the structure of Latin American economies, but contains policies implications that would reinforce the existing institutional framework." 20

A referência à CEPAL e à teoria da dependência surge assim, descuidada, como descuidado é o uso que North faz da ilustração histórica quando busca contrastes para tipificar os casos bem-sucedidos que estudou e que toma como modelares. Excetuando o paralelo antigo com a Espanha imperial, ao longo de todo o texto o lugar do outro é preenchido em seu livro por essa entidade amorfa: o Terceiro Mundo. Quando se trata de especificar um pouco mais, o alvo predileto é a América Latina. No pólo oposto, salvo uma ou outra menção à Europa continental, os exemplos invocados vêm da Inglaterra e dos Estados Unidos. Salvo engano, nenhuma alusão ao Japão, à Coréia, ou a qualquer país asiático.

Não chamamos a atenção para esse aspecto a título de denúncia, embora a carga de preconceito contida no livro de North seja inaceitável, ainda que apenas por violar os requisitos mínimos de seriedade intelectual. Concluída a apresentação da obra, levantar o assunto é conveniente porque nos conduz ao primeiro dos comentários com os quais encerraremos este trabalho.

Ele tem a ver com a modalidade de comparação histórica presente no trabalho de North. Como vimos, o ponto de partida de sua reflexão é o contraste inicial que faz entre o caso exitoso da Inglaterra e o da trajetória declinante da Espanha. Como vimos também, a razão que encontra para explicar um e outro - o sucesso e o fracasso - são eminentemente endógenas: as respectivas estruturas institucionais, os direitos de propriedade nelas embutidos. Neste livro, as comparações são da mesma ordem - de um lado, a moldura institucional dos países avançados, que asseguram aqueles direitos, criando um ambiente propício à atividade produtiva, ao reduzir a incerteza e estender, dessa forma, o horizonte temporal dos atores; de outro, o Terceiro Mundo, a América Latina, a África, onde essas condições não prevalecem, com as conseqüências nefastas consabidas. Mas ao fazer isso North trata os sistemas nacionais como entidades discretas, apenas externamente relacionadas. Ora, a economia capitalista já nasceu como economia internacional. O comércio a longa distância, as redes combinando extensas cadeias de trocas, a mobilização de recursos para a implantação de unidades produtivas em terras distantes, tudo isso precede a constituição plena dos mercados nacionais. O erro metodológico consiste em tomar como unidades de análise independentes conjuntos sociais

${ }^{20}$ Ibid., pp. 99-100. 
que só fazem sentido como elementos de um sistema maior que os envolve. ${ }^{21}$ No tocante a alguns deles, a simples delimitação de suas fronteiras empíricas - ou seja, sua mera identificação como unidades de observação - é mais do que problemática. Este é o caso da Espanha no século XVI, parte, ainda que central, de um vasto império; parcelada em jurisdições distintas e submetida politicamente à lógica das alianças dinásticas.

A sentença condenatória que North profere sumariamente contra a CEPAL e a teoria da dependência reflete, portanto, algo mais do que preconceito. É que, para além de seus méritos e de seus defeitos, ambas apontam para uma dimensão inteiramente ausente em seu quadro de referência, que correria o risco de implodir se solicitado a integrá-la.

Esse juízo nos leva ao segundo comentário. Vimos ao longo da exposição como a troca impessoal, na análise de North (mas aqui ela nada tem de original), requer a intervenção de uma terceira parte que se encarregue de resolver conflitos de interpretação e de garantir o cumprimento dos contratos. Ora, contratos, direitos de propriedade são elementos constitutivos das transações interfronteiriças. E muito cedo deram origem a esforços concentrados de sistematização legal. Mas é exatamente aí que mora o problema: na arena internacional o terceiro ator, suficientemente forte e imparcial para terminar litígios e fazer valer os direitos estabelecidos, não existe. No plano internacional o que temos é, na melhor das hipóteses, um sistema de direito primitivo, no qual a competência das cortes é restrita, sua independência é precária, e a sanção está a cargo das partes envolvidas. Ora, como ficou sobejamente demonstrado nas páginas de North, em um mundo assim predomina a lei do mais forte e viceja o oportunismo.

Nessas páginas finais não poderemos extrair todas as conseqüências desse fato, mas alimentamos forte suspeitas de que elas incidiriam sobre o esquema de North de maneira assaz subversiva.

Entre outras coisas, porque poria em evidência esse aspecto: a teoria da mudança institucional de North ignora o papel decisivo dos movimentos, as iniciativas, os resultados dos "encontros" que ocorrem no desenrolar do conflito. Em outras palavras, o esquema de North inclui o conflito, mas o mantém como uma caixapreta: dado o descompasso entre as novas situações criadas pelo processo econômico e os marcos institucionais que continuam a encerrá-lo, esforços coletivos tendem a surgir com o objetivo de mudá-los. Mas em relação ao processo, necessariamente conflitante, de mudança mesmo tudo o que o modelo tem a dizer é aquela obviedade já refe-

\footnotetext{
${ }^{21}$ Esta a objeção levantada por Wallerstein contra o procedimento comparativo típico das teorias da modernização tão em voga nos Estados Unidos nos anos 60. Cf. Immanuel Wallerstein, The Modern World System: Capitalist Agriculture and the Origins of the European World Economy in the Sixteenth Century. New York, Academic Press, 1974. Para uma discussão desse argumento de Wallerstein, cf. Charles Ragin e Daniel Chirot, "The world system of Immanuel Wallerstein: sociology and politics as history", in Theda Skocpol (ed.), Vision and Method in Historical Sociology. Cambridge, Cambridge University Press, 1989, pp. 276-312, e Charles Ragin, The Comparative Method: Moving Beyond Qualitative and Quantitative Strategies. Berkeley, University of California Press, 1989.
} 
rida: seu resultado depende do poder de barganha das partes. Em termos ideais, conhecida a situação antecedente e o poder de barganha dos atores em causa, seria possível deduzir o resultado do conflito e, logo, o sentido e o alcance da mudança institucional. Ora, para o político e - seria de esperar - para a ciência política, o que fica de fora é o principal. Vale dizer o conflito em sua dinâmica própria, como produtor de efeitos de realidade — entre eles, a redefinição dos objetivos perseguidos pelos atores envolvidos, suas "preferências" e mesmo sua identidade. Essa, a principal objeção levantada por Charles Tilly às tentativas de aplicação do modelo da escolha racional em estudos sobre a formação do Estado;22é ela que se expressa no comentário de Wendt sobre as limitações de abordagens afins à de North no campo das relações internacionais, que passo a citar.

"An important but neglected feature of the recent debate is the shared belief that collective action should be analysed in terms of Mancur Olson's definition of the problem.... While some neoliberal have questioned the assumption of state egoism..., few treat state interests as endogenous to interaction. They either bracket the formation of interests, treating them as if they were exougenous, or explain interests by reference to domestic politics... In both cases, the effect on systematic theory is captured by what Jeffrey Legro calls the rationalist "two step": first interests are formed outside the interaction context, and then the latter is treated as though if only affected behavior." 23

E não é só isso. Ao estancar no instante exato em que esboça o conflito, North deixa de considerar a maneira como agem os atores quando mergulhados em situações de crise. Nas crises a incerteza se eleva e pode atingir níveis intoleráveis em seus momentos de pico. $\mathrm{O}$ argumento de North nos diz como tudo termina: ao fim e ao cabo, instituições serão criadas, ficando domada a incerteza no quadro de um novo equilíbrio. Mas essa solução não mata nossa curiosidade. Ela toma como certo um resultado que, absolutamente, não está de antemão garantido. Ademais, ela parece desconhecer que em situações desse tipo, um dos componentes principais do problema é a disputa entre diferentes soluções institucionais para a crise. Por fim, ela é cega para o que há de mais importante em momentos decisivos: o elemento de surpresa tática, o lance desconcertante - que "inverte o jogo, ou cria um jogo novo". De uma forma ou outra, que produz uma situação imprevista. ${ }^{24}$

\footnotetext{
${ }^{22}$ Charles Tilly, "Prisioners of the State”, Daedalus. International Social Science Journal, 133, 1992, pp. 329-42.

${ }^{23}$ Alexander Wendt, "Collective identity formation and the International State", American Political Science Review, 88, (2) 1994, pp. 384-96 (citação p. 384). Cf., do mesmo autor, "Anarchy is what States make of it: the social construction of power politics”, International Organization, 46 (2) 1992, pp. 391-425, e Barry Hindess, "Power, interests and the outcome of struggles", Sociology, 16 (4), 1982, pp. 498-511; “Analysing actor's choices”, International Political Science Review, 1990, pp. 87-97.

${ }^{24}$ A história militar e política está repleta de casos desse tipo. Mas eles ocorrem igualmente, em
} 
As situações de crise são férteis em acontecimentos desse tipo. Mas eles ocorrem, igualmente, em contextos de relativa "normalidade". A consideração do conflito Brasil-Estados Unidos em matéria de propriedade intelectual nos fornece uma ilustração eloqüente dessa verdade. Quando o governo norte-americano abriu um processo na OMC contra o dispositivo da lei brasileira que facultava a quebra de patentes de remédios em casos tidos como de emergência, ele dava início a mais uma das muitas pendências a compor o contencioso comercial entre os dois países. E, como em situações precedentes, a assimetria entre os dois contendores não augurava nada de bom para as teses brasileiras. Ao colocar a questão no terreno do combate à AIDS, o Brasil não se limitou a realizar um "lance" bem-sucedido em um jogo cujas regras estavam previamente dadas. Ele alterou a natureza do conflito, estendendo-o a outras "arenas" (a ONU, a Organização Mundial da Saúde), introduzindo novos atores (ONGs, vários governos, segmentos importantes da opinião pública nos países desenvolvidos) e pondo em cena um princípio maior do que o direito de propriedade - o direito à vida -, que se articula em uma outra linguagem: a linguagem dos direitos humanos. Nesse terreno, como pudemos ver, o embate não era tão desigual.

E por aí chegamos à observação telegráfica com a qual se encerrará este artigo. Como se sabe, desde meados da década de 70 a economia mundial vem atravessando um processo de mudança institucional de amplitude e profundidade ímpares. Com tudo que nela há de impreciso, é a percepção da magnitude, do ritmo e de algumas das tendências mais salientes em tal processo que se expressa na universalização do vocábulo globalização. O rompimento unilateral, em 1971, do compromisso que atava o dólar ao ouro é um dos marcos desse processo. As políticas de liberalização financeira, adotadas pela Inglaterra e pelos Estados Unidos, constituem um outro. Parte decisiva na transformação de conjunto a que assistimos vem cabendo às reformas liberalizantes implantadas, em curto lapso de tempo, na quase totalidade dos países do assim chamado Terceiro Mundo, com alcance diferente e grau variável de sucesso. $\mathrm{O}$ mesmo com a cautelosa política de abertura praticada pelo Japão e outros países asiáticos. O forte elemento volitivo, o monitoramento permanente e a propagação avassaladora de um discurso padronizado sobre as virtudes, a direção e as exigências desse processo dão a este seu colorido ideológico particular. Daí o atrativo da fórmula globalização-neoliberalismo. Pois bem, tais fenômenos nos confrontam com o desafio intelectual/prático de tentar entender esse movimento geral de mudança, explicar as discrepâncias observáveis entre diferentes países e regiões, identificar as forças que o promovem e as resistências que encontram, na expectativa de, com os avanços feitos nesse sentido, poder antecipar a emergência de fenômenos e tendências novos — ou, quando por eles surpreendidos, aquilatar-lhes o significado.

No início deste artigo tivemos o cuidado de estipular uma regra bem definida

diferentes escalas, no mundo dos negócios e no terreno da macroeconomia. Cf., a esse respeito, G. L. S. Shackle, op. cit., capítulo 36, "La excluisón de la surpresa tactica en la teoria de los juegos". 
com o fim de melhor controlar o risco sempre presente em exercícios como o nosso de condenar um autor por não ter feito aquilo que não constava de seus propósitos. Mas agora, no fim do caminho, e à luz dos elementos reunidos durante o percurso, podemos afirmar sem medo de cometer injustiças: se quisermos formular uma teoria geral da mudança institucional (ainda que restrita ao domínio da economia), não podemos abstrair as instituições que conformam a economia mundial. O fato de North não focalizá-las não é resultado de uma simples “decisão", a qual deveríamos reconhecer e respeitar. O silêncio nesse particular não é fortuito: ele reflete graves insuficiências no quadro de referência do autor, que ficam evidentes quando tentamos estendê-lo para fazer face àquele repto. 